\title{
EDUCAÇÃO POPULAR, AÇÕES EM SAÚDE, DEMANDAS E INTERVENÇÕES SOCIAIS: O PAPEL DOS AGENTES COMUNITÁRIOS DE SAÚDE*
}

\author{
Ana Paula Serrata Malfitano ${ }^{* *}$ \\ ROSELI ESQUERDO LOPES ${ }^{* * *}$
}

\begin{abstract}
RESUMO: Trata-se da análise da intervenção dos agentes comunitários de saúde (ACS) do Programa de Saúde da Família, com relação a demandas sociais, tendo como base uma região do centro expandido de São Paulo, caracterizada pela presença de cortiços e ex-cortiços e de movimento popular de luta por moradia. Essa região contava com a atuação de cinco ACS, dos quais três eram lideranças do movimento social. As análises focalizaram a dimensão da educação popular oriunda da participação no movimento social, a partir de seus militantes que desempenhavam a função de ACS. Objetivou-se apreender se a implantação de políticas e programas sociais possibilita a produção de formas de consolidação das redes sociais de suporte para aqueles em situação de vulnerabilidade social. Trabalhou-se com pesquisa participante, entrevistas e observação. Aponta-se que as políticas e os programas sociais poderão atuar nas redes sociais se ampliarem seus horizontes de intervenção e buscarem a ação intersetorial.
\end{abstract}

Palavras-chave: Políticas públicas. Movimentos sociais. Educação popular. Programa de Saúde da Família. Intervenções sociais.

* Pesquisa desenvolvida com o apoio da CAPES e do CNPq.

** Professora adjunta do Departamento de Terapia Ocupacional da Universidade Federal de São Carlos (UFSCAR).E-mail: anamalfitano@ufscar.br

*** Professora associada do Departamento de Terapia Ocupacional e do Programa de Pós-Graduação em Educação da UfSCAR. E-mail: relopes@ufscar.br 
Educação popular, ações em saúde, demandas e intervenções sociais...

Popular EDUCATION, ACTIONS IN HEALTH, DEMANDS AND SOCIAL INTERVENTIONS: THE ROLE OF HEALTH COMMUNITY AGENTS (HCAS)

ABSTRACT: This paper analyzes the intervention of Health Community Agents (HCAs) from the Family Health Program, with regard to social demands. Our reference is a region of São Paulo's extended center characterized by the presence of tenement houses, former tenement houses and popular movements for housing. It counts on five HCAs, three of which are social movement leaders. The analyses focused on the dimension of popular education that derives from the participation in social movements, as characterized by the actions of these three militants who are also HCAs. Though participative research, interviews and direct observation, we strove to know whether implementing social policies and programs allowed to produce and consolidate social support nets for those in situation of social vulnerability. We concluded that social policies and programs will only be effective in social nets if they extend their intervention objectives and if look for intersectoral action.

Key words: Public policies. Social movements. Popular education. Family Health Program. Social interventions.

\section{Apresentação}

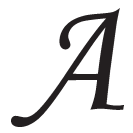

temática das "políticas públicas" e dos "movimentos sociais" tem apresentado destacada relevância no cenário atual, por ser fundamental no debate acerca do papel do Estado, das políticas em desenvolvimento, da participação social e da sociedade civil, esferas que interferem diretamente na dinâmica social.

Tomando como fundamentos os princípios freireanos da educação popular e suas articulações com os movimentos sociais, objetivamos analisar a produção (ou não) de mudanças significativas em comunidades em situação de vulnerabilidade social, a partir da implementação de políticas e projetos sociais. Neste estudo, destacamos a intervenção de agentes comunitários de saúde (ACS) oriundos do movimento popular por moradia e as possibilidades e os limites de sua intervenção, com relação a demandas sociais que lhe são apresentadas pela comunidade no cotidiano do processo de trabalho. A região em que realizamos a pesquisa de campo localiza-se no centro expandido da cidade de São 
Paulo (SP) - região do Brás e do Belém -, composta por bolsões de pobreza, contando com a presença de cortiços, ex-cortiços e com a ação do movimento social de luta por moradia urbana. Metodologicamente, o trabalho foi estruturado num diálogo com a pesquisa participante, na medida em que compúnhamos aquele território na qualidade de operadora social em um projeto comunitário. Lançamos mão da realização de entrevistas semiestruturadas com os diversos atores do Programa de Saúde da Família - dos gestores aos usuários - e de observação participante junto às ações dos ACs. Tais recursos e inserção nos possibilitaram um trânsito que, a todo momento, nos convidava à reflexão acerca das experiências realizadas no ambiente microssocial e suas conexões com o contexto macrossocial das políticas públicas.

Educação popular e a proposta do Programa de Saúde da Família

\section{O Programa de Saúde da Família (PSF)}

O PSF, segundo o Ministério da Saúde, se traduz como "uma estratégia que prioriza as ações de promoção, proteção e recuperação da saúde dos indivíduos e da família, do recém-nascido ao idoso, sadios ou doentes, de forma integral e contínua" (Brasil, 2003). O atendimento é prestado na Unidade de Saúde da Família e, também, no domicílio das famílias atendidas pela equipe de saúde da família. A equipe mínima é composta por um médico generalista, um enfermeiro, um auxiliar de enfermagem e de quatro a seis agentes comunitário de saúde (ACS) (Brasil, 2001a).

O ACs é uma pessoa da própria comunidade que recebe qualificação específica, passando a fazer parte da equipe de saúde local; atende aos moradores em cada casa, dando atenção a todas as questões relacionadas à saúde: identifica problemas, orienta, encaminha e acompanha a realização dos procedimentos necessários à proteção, promoção e recuperação/reabilitação da saúde das pessoas daquela comunidade. Exige-se do ACS a residência na comunidade há pelo menos dois anos, que tenha 18 anos ou mais, que saiba ler e escrever e que tenha disponibilidade de tempo integral (Brasil, 2001b).

O PSF enraizou-se como uma política nacional na atenção à saúde das pessoas, mesmo com mudanças de gestão nas cidades e até no 
Educação popular, ações em saúde, demandas e intervençôes sociais...

Ministério da Saúde. Isso se deu, entre outros fatores, pelos incentivos financeiros promovidos pelo Ministério desde o início de sua implantação na última década de noventa, levando à continuidade da diretriz de atenção básica pela via do PSF, estratégia escolhida para o desenvolvimento das ações primárias de saúde no Brasil. Assim, o ACS integra essa estratégia de intervenção na atenção básica, sendo o elo intermediário entre a comunidade e os serviços.

\section{Educação popular em saúde}

A educação popular em saúde define-se como um "campo de prática e conhecimento que se ocupa com a ligação entre a ação de saúde e o pensar e o fazer do dia a dia da população" (Sophia, 2001, p. 5). Essa experiência acontece quando o trabalho profissional entra em diálogo com a cultura popular.

Vale lembrar que o estímulo à participação e à organização popular não está relacionado somente com processos pedagógicos e de protagonismos, mas, também, com a ausência do Estado e com o não cumprimento de seu papel para o desenvolvimento de políticas públicas, pois, muitas vezes, “(...) as autoridades querem a participaçã̃o popular para solucionar problemas para os quais não dão conta” (Valla, 2000, p. 21). Vasconcelos (2001a, p. 15) diz que a educação popular:

(...) busca trabalhar pedagogicamente o homem e os grupos envolvidos no processo de participação popular, fomentando formas coletivas de aprendizado e investigação de modo que promova o crescimento da capacidade de análise crítica sobre a realidade e o aperfeiçoamento das estratégias de luta e enfrentamento.

Contextualiza-se, portanto, algumas experiências de educação popular - como aquelas relacionadas às intervençóes coletivas dos movimentos sociais - na dimensão da educação não-formal, a partir das lutas cotidianas. Estas se constituem como um dos elementos para um processo de educação através das ações coletivas, que têm a luta pela cidadania como objeto impulsionador de suas práticas, sendo a conscientização e a ação coletiva, a partir de um grupo social oriundo, na maioria das vezes, de classes populares, sua maior característica. "A educação não-formal tem sempre um caráter coletivo, passa por um 
processo de ação grupal, é vivida como práxis concreta de um grupo" (Gohn, 1999, p. 104).

Chiesa e Veríssimo (2001) vêem no PSF um espaço privilegiado para o desenvolvimento da prática educativa, possibilitando a ampliação e fortalecimento da participação comunitária.

O ACs tem a função de acompanhar as famílias de sua comunidade, ofertando informações, intervindo em processos educativos, possibilitando o acesso até a unidade de saúde, realizando ações de pequena complexidade, viabilizando a entrada do profissional na casa das pessoas, entre outras. Também lhes é atribuído o papel de incentivo à participação comunitária e ao desenvolvimento da organização local.

A região de nosso estudo insere-se num território ${ }^{1}$ em que a maioria dos ACS é liderança local em seu contexto. Essa particularidade facilita algumas dimensóes pensadas para o trabalho do ACS; as próprias diretrizes do Ministério da Saúde para o PSF propõem a valorização desse perfil, apostando nas potencialidades desta característica para a promoção de ações em educação e saúde. Contudo, tal fato por si só não garante a operacionalização de processos de educação popular, participação e desenvolvimento comunitário a partir do PSF. É necessário, também, um investimento do nível gestor, potencializando a particularidade local, campo em que as ações encontram-se facilitadas pela presença do movimento social popular, incentivando, efetivamente, a promoção dos processos de trabalho fundamentados nessa vertente.

A educação popular em saúde coloca para o PSF uma possibilidade de operacionalização. Pode-se dizer que o desenvolvimento de ações de educação popular trata-se, mesmo, de uma das estratégias políticas do PSF que, entretanto, requer formação e investimento nesse princípio como diretriz para o seu desenvolvimento.

\section{Atrás da porta que se abre}

O PSF na região do Belém: ${ }^{2}$ os agentes comunitários de saúde e as demandas para além da saúde

Uma das indagações da investigação foi conhecer quais são as formas de encaminhamento dadas pelo PSF para as demandas que não se caracterizam como estritamente ligadas à saúde. 
Educação popular, ações em saúde, demandas e intervençôes sociais...

O PSF apresenta um discurso de promoção de ações segundo as necessidades de cada comunidade, devendo ofertar alto índice de resolubilidade, em conformidade com os preceitos anteriormente estabelecidos sobre atenção básica em saúde ou atenção primária. $\mathrm{O}$ intuito é responder às demandas locais, que serão variadas de acordo com a realidade de cada território, por meio das ações de prevenção à reabilitação, a partir de valores como a solidariedade e a equidade, que lancem mão de estratégias para o estabelecimento de intervenções intersetoriais, com participação popular, que culminem no direito à saúde em seu mais alto nível, segundo o modelo em defesa da vida (Andrade, Barreto \& Bezerra, 2006).

Tem-se, contudo, uma contradição entre aquilo que é oficialmente definido e o que é concretamente ofertado para a população através do PSF. O ACS é o elo inicial do trabalho, aquele que recebe e encaminha as demandas individuais e coletivas da comunidade, bem como aquele que será o principal porta-voz do modelo de saúde que se implementa.

A comunidade em que trabalhamos tem a particularidade de pertencer a um território com a experiência do movimento social de luta por moradia e três de suas lideranças estão na função de ACS, em diferentes equipes que compóem o PSF.

A presença dos cortiços - especialmente daqueles ligados ao movimento de moradia - e a entrada dos ACs em tais espaços têm possibilitado que a discussão do direito à assistência em saúde se dê em um lugar onde a população raramente chega até os equipamentos, principalmente devido ao estigma que trazem consigo por serem moradores de cortiços.

$\mathrm{Na}$ promoção do acesso de todos aos serviços de saúde, as intervenções priorizam as questôes de saúde básica, naquilo que se configura nas ações cotidianas do trabalho. São investigadas as possibilidades de doenças, auxilia-se na detecção de problemas, encaminha-se para procedimentos de tratamentos. Essas são tarefas importantes do ACS, uma vez que, através dessa intervenção, ele ajuda a melhorar os indicadores epidemiológicos de sua comunidade.

Porém, as demandas que chegam ao ACS não se restringem às ações de saúde básica, nem sequer ao campo da saúde. O ACs é visto pelo seu vizinho como alguém que pode auxiliá-lo, pois está inserido 
em um serviço público, o que facilita a comunicação e a apresentação de suas demandas naquele momento, demandas estas que podem ou não estar relacionadas a ações de saúde básica, mas que são, na maioria das vezes, ações sociais básicas.

Quando perguntamos aos ACS quais eram as maiores demandas locais, eles pontuaram: "as relacionadas à saúde?". Na sequência, enumeraram as incidências epidemiológicas de sua comunidade; logo depois, entretanto, apontaram "outras demandas” nas quais são chamados a intervir, tais como: casos de pessoas portadoras de deficiência ou transtorno mental, a questão da violência doméstica, das drogas, do cortiço, da fome, da falta de vaga em creches etc.

As demandas que ultrapassam o âmbito da saúde básica são, muitas vezes, encaminhadas para outros serviços e não são reconhecidas como trabalho da alçada do ACS, como parte de sua função. No cotidiano concreto observado, não há a leitura do atendimento às demandas sociais como possibilidade de intervenção do âmbito do PSF, sendo que isso se dá com relação à coordenação do Programa na região, aos demais profissionais da equipe e, consequentemente, ao próprio ACS.

Os ACs buscam informações com os profissionais da equipe, pedem apoio para esclarecimento de problemáticas com as quais se defrontam e que não cabem nos moldes estabelecidos na saúde, perguntam sobre demais equipamentos sociais que desconhecem e orientam a população. A maioria deles, no entanto, só reconhece a sua ação profissional quando se trata de encaminhamentos para os serviços de saúde. A discussão da promoção de demais ações não está no rol daquilo que por eles é reconhecido como trabalho, fazendo-se, contudo, bastante presente na prática cotidiana.

O ACs faz parte, muitas vezes, da rede pessoal daquele que ele atende, agora profissionalmente. Por sua característica de liderança, no caso da região que estudamos, sua participação local antecede - evidentemente, em outro nível e qualidade de comprometimento - a sua função como ACs. Ele já é conhecido, tem vínculos, entra na casa das pessoas com outros recursos e disponibilidades.

Castel (1994 e 1997) compreende as redes sociais e pessoais de suporte como elementos fundamentais na definição de maior ou menor vulnerabilidade daquele que tem uma integração precária ao mundo do trabalho. 
Educação popular, ações em saúde, demandas e intervençôes sociais...

Uma boa inserção relacional sociofamiliar pode compensar e/ou minimizar os efeitos de uma situação de não-integração nas relações de trabalho. Ou seja, a dimensão econômica, que no caso das classes populares passa pelo acesso ao trabalho/emprego, embora fundamental, não é determinante. Para essas classes, "sempre mais ou menos pobres", na medida em que não dispõem dos meios de produção para o trabalho, o coeficiente de inserção social pode posicionar seus indivíduos em espaços menos vulneráveis (Lopes, 2007).

O espaço comunitário desses ACs inscreve-se, na maioria das vezes, em uma zona de vulnerabilidade relacional, ${ }^{3}$ tendo a política do PSF a possibilidade, caso ultrapasse os limites da saúde básica, de contribuir para o fortalecimento das redes sociais comunitárias de suporte. O escopo de ação pode ser ampliado a partir do campo da saúde e criar desdobramentos que interfiram no cotidiano e vida das pessoas em outros aspectos, atuando nas suas redes pessoais, produzindo significantes não só objetivos, mas também subjetivos, potencializando a ação dessa política pública.

O trabalho de acompanhamento das famílias que vivem em situação de vulnerabilidade social, "numa perspectiva de não se restringir ao controle de problemas de saúde específicos", busca "apoiar a luta desses moradores pela vida, entendida de forma mais ampla" (Vasconcelos, 2001b, p. 152). O problema destas famílias nem sempre poderão ser "curados", mas certamente poderão ser "cuidados" (idem, ibid.).

A atuação a partir dessa perspectiva utiliza como eixo a educação, nos preceitos da autonomia, liberdade e criatividade, baseados em Paulo Freire (1978, 1979a, 1979b), os quais prevêem que o alcance dos objetivos do trabalho dar-se-á a partir do conhecimento local e das potencialidades ali presentes, de maneira que se articulem, com base no que define e cria a comunidade, possibilidades de tessitura de projetos autônomos de vida.

Os limites das ações no campo da saúde e a necessidade de discussão de um escopo mais amplo são, também, parte da fala de alguns ACS. Tem-se, portanto, pautada a discussão da intersetorialidade como elemento potencializador das ações em políticas públicas, analisando, neste caso, uma política de saúde e almejando um desenho mais de acordo com as necessidades socialmente colocadas do PSF, o que poderia resultar em benefícios para a população atendida. Nessa discussão, 
o ACS pode ocupar um espaço fundamental como mediador entre a comunidade e o poder público, ampliando suas funções para um agente comunitário social, articulador de melhorias, contribuindo para a eficácia das políticas sociais no nível local.

A ressignificação do paradigma norteador das ações do PSF, ressaltando a importância do papel do ACS, pode vir a ser um importante instrumento para o fortalecimento das redes sociais de suporte da população atendida.

\section{Considerações finais}

A avaliação e a análise das políticas presentes nos cenários nacional e local são necessárias para que se tenha elementos que informem acerca das convergências e divergências entre o planejamento e a execuções dos diferentes projetos em andamento, bem como sobre a mudança (ou não) criada nos espaços em que atuam.

Quando se busca compreender o campo da política e seus diferentes núcleos que se debruçam sobre as questóes sociais brasileiras, vislumbra-se conhecer as possibilidades de intervenções para diminuição das desigualdades sociais. O estudo de tal contexto ocupa um locus de significância sublinhada na sociedade, principalmente quando demarcada por forte desigualdade social.

A partir da análise realizada, com base nos eixos da política pública e do movimento social, pudemos observar que, no atual contexto sociopolítico, a participação social - dada através da articulação entre Estado e sociedade civil e da interferência da última nas políticas públicas - faz-se de forma precária e pouco sistemática no cotidiano.

As políticas sociais encontram-se, por sua vez, implementando ações focais dentro de uma ordem neoliberal, limitando seu escopo de atuação. Planejam-se, algumas vezes, intervenções numa dimensão agregadora de diferentes setores, mas são executadas ações simplificadas.

$\mathrm{Na}$ junção da análise destes dois relevantes componentes sociais, políticas públicas e movimentos sociais, observa-se, em ambos, possibilidades de intervenção numa perspectiva ampliada que busque atingir a transformação do quadro social vivenciado. Essas possibilidades serão potencializadas se atuarem conjuntamente. 
Educação popular, ações em saúde, demandas e intervençôes sociais...

Todavia, não nos deparamos com a efetivação de intervenções sociais que ultrapassassem os limites de seu núcleo de atuação naquele território. Encontramos, apenas, ações isoladas e pontuais como resposta para as necessidades da população, restritas aos seus limites, sem configurar-se de modo a atingir as potencialidades dessas intervenções.

Isso nos faz concluir que a criação e/ou a ampliação das redes sociais de suporte pelas políticas e projetos atuais dão-se de maneira individualizada, particular, segmentada, criando micromarcas nas histórias de vidas de algumas pessoas que as vivenciaram. Porém, não há estrutura para a construção de macroações nas redes sociais de suporte de comunidades em situação de vulnerabilidade.

A não-criação de ações generalizadas para a comunidade ocorre pela dificuldade de efetivação da intersetorialidade no cotidiano do trabalho, pela não-ampliação do escopo de atuação dos projetos em desenvolvimento, pela não-priorização de ações com grupos "apenas" vulneráveis socialmente. O campo social é, na nossa visão, um campo interdisciplinar e intersetorial, no qual se insere a atuação de caráter comunitário.

As ações desenvolvidas, na comunidade que acompanhamos, mostraram potenciais de produção de resultados efetivos, podendo vir a criar modificaçóes nas redes sociais de suporte daquele grupo, sem a necessidade de alto investimento tecnológico e de recursos materiais e financeiros de grande monta.

Dentro dessa perspectiva, a educação popular assume papel central como instrumento para articulação, reivindicação, participação e influência nas políticas sociais em desenvolvimento.

Ações em meio aberto, como as realizadas pelos ACs, devem priorizar o cuidado, dentro da sua dimensão pedagógica, segundo as necessidades do grupo atendido.

Acreditamos que as políticas públicas, com enfoque nas de recorte social - quando implementadas a partir de uma ótica nãorestritiva, que promova e viabilize as açóes interdisciplinares e intersetoriais, a valorização da educação popular e da dimensão do cuidado -, possibilitarão a concretização de intervenções que efetivamente atuem numa perspectiva coletiva, para a produção de significantes e 
significados que interfiram na criação e ampliação das redes sociais de suporte de grupos em situação de vulnerabilidade social.

\section{Recebido em abril de 2008 e aprovado em maio de 2009.}

\section{Notas}

1. A noção de território aqui utilizada considera não só a delimitação geográfica de uma região, princípio de divisão de áreas de abrangência das equipes do PSF, mas pressupōe sua constituição histórica e as relaçôes socioeconômicas e culturais ali desenvolvidas.

2. O local dos estudos de campo foi a região do Brás, centro expandido da cidade de São Paulo, fruto da industrialização paulista e de seus processos com relação aos trabalhadores e suas vilas operárias, os casarões patronais e os espaços e depósitos industriais. Atualmente, apresenta um decréscimo da população que ali reside, sendo muito mais caracterizada pelo trânsito cotidiano e fluxos de trabalho.

3. O conceito de vulnerabilidade aqui utilizado baseia-se nos trabalhos de Castel (1994, 1997). A inserção social, para o autor, deve ser analisada a partir de dois eixos: o da relação de trabalho (com uma gama de posições do emprego estável à ausência completa de trabalho, passando por formas precárias de ocupação) e o da inserção relacional (também com um leque de posições entre a inscrição nas redes sólidas de sociabilidade e o isolamento social total). O recorte desses eixos circunscreve zonas diferentes do espaço social: integração; vulnerabilidade; assistência e desfiliação.

\section{Referências}

ANDRADE, L.O.M.; BARRETO, I.C.H.C.; BEZERRA, R.C. Atenção primária em saúde e a estratégia de saúde da família. In: CAMPOS, G.W.S. et al. (Org.). Tratado de saúde coletiva. Rio de Janeiro: FIOCRUZ, 2006. p. 783-836.

BRASIL. Ministério da Saúde. Programa de Saúde da Família. Disponível em: <http://www.saude.gov.br/psf>. Acesso em: abr. 2003.

BRASIL. Ministério da Saúde. Secretaria Executiva. Programa Saúde da Família. Brasília, DF: Ministério da Saúde, 2001a.

BRASIL. Ministério da Saúde. Departamento de Atenção Básica. Guia prático do Programa de Saúde da Família. Brasília, DF: Ministério da Saúde, 2001b.

CASTEL, R. Da indigência à exclusão, a desfiliação: precariedade do trabalho e vulnerabilidade relacional. In: LancetTi, A. (Org.). Saúde loucura. São Paulo: HUCiTec, 1994. p. 21-48. 
Educação popular, ações em saúde, demandas e intervenções sociais...

CASTEL, R. As dinâmicas do processo de marginalização: da vulnerabilidade à desfiliação. Cadernos $C R H$, Salvador, n. 26/27, p. 1940, jan./dez. 1997.

CHIESA, A.M.; VERÍSSIMO, M.D.L.O.R. A educação em saúde na prática do PSF. In: Manual de condutas de enfermagem: programa de saúde da família. São Paulo: Instituto para o Desenvolvimento da Saúde; UsP, 2001. p. 34-42.

COHN, A.; ELIAS, P. Saúde no Brasil: políticas e organização dos serviços. São Paulo: Cortez; CEDEC, 1996.

FREIRE, P. Ação cultural para a liberdade e outros escritos. Rio de Janeiro: Paz \& Terra, 1978.

FREIRE, P. Pedagogia do oprimido. 7. ed. Rio de Janeiro: Paz \& Terra, 1979a.

FREIRE, P. Educação como prática da liberdade. 9. ed. Rio de Janeiro: Paz \& Terra, 1979b.

GOHN, M.G. Educação não-formal e cultura política. São Paulo: Cortez, 1999. (Questões da nossa época; v. 71).

LOPES, R.E. Redes sociais de suporte. In: Park, M.B.; Fernandes, R.S.; Carnicel, A. Palavras-chave em educação não-formal. Holambra: Setembro; Campinas: UNICAMP, 2007.

SOPHIA, D. Os homens se educam entre si, mediatizados pelo mundo. Revista Tema: Educação Popular em Saúde, Rio de Janeiro, n. 21, p. 4-6, nov./dez. 2001.

VALLA, V.V. Procurando compreender a fala das classes populares. In: Valla, V.V. (Org.). Saúde e educação. Rio de Janeiro: DP\&A, 2000. p. $11-32$.

VASCONCELOS, E.M. Redefinido as práticas de saúde a partir da educação popular nos serviços de saúde. In: VAsConcelos, E.M. (Org.). A saúde nas palavras e nos gestos: reflexões da rede de educação popular e saúde. São Paulo: HUCITEC, 2001a. p. 11-20.

VASCONCELOS, E.M. Educação popular e a atenção à saúde da família. 2. ed. São Paulo: HUCıTec, 2001 b. 